\title{
Does Emotional Intelligence Influence Employees, Customers and Operational Efficiency? An Empirical Validation
}

\author{
Mohammad Sultan Ahmad Ansari ${ }^{1}$, Jamal Ahmad Farooquie ${ }^{2}$ \& Said M. Gattoufi ${ }^{3}$ \\ ${ }^{1}$ Oman Telecommunications Co., Oman \\ ${ }^{2}$ Department of Business Administration, Aligarh Muslim University, Aligarh, India \\ ${ }^{3}$ Institut Superieur de gestion de Tunis, Universite de Tunis, Tunisia \\ Correspondence: Mohammad Sultan Ahmad Ansari, Manager, Oman Telecommunications Co., Oman. E-mail: \\ sultan_a_ansari@yahoo.com
}

Received: August 7, 2016

Accepted: October 25, 2016 Online Published: November 28, 2016

doi:10.5539/ijms.v8n6p77

URL: http://dx.doi.org/10.5539/ijms.v8n6p77

\begin{abstract}
A research study was initiated to investigate the impact of emotional intelligence on employees' satisfaction and loyalty, and how it influences operational efficiency in telecom service industry in Oman. A questionnaire-based survey was conducted and the responses received were tested with various statistical techniques. These test results were found to be in broad agreement with the assumptions widely prevalent in management literature and service industries.

The findings suggest that emotional intelligence contributes significantly in improving internal performance. Employees are valuable assets and improved internal performance is due to employees' commitment. Service industry could take care of employees, keep them satisfied to win their loyalty, which can be achieved through regular employees' engagement and involvement. Engaged employees value customers' expectations and build better relationship. Satisfied and loyal employees are in a position to deliver high service quality and improved productivity. The service provider shall continuously monitor service quality to maintain end users' satisfaction. It can be sustained through employees' continuous training and skills development that will improve operational efficiency of the company in terms of increased sales and profitability. Thus, the present study provides an empirical validation and confirmation of the propositions and hypotheses about how service providers should manage employees' emotional intelligence for giving them satisfaction, winning their loyalty, thereby, eventually enhancing service values, operational efficiency and profitability of the company.
\end{abstract}

Keywords: customer loyalty, customer satisfaction, emotional intelligence, employee loyalty, employee satisfaction, operational efficiency, service quality

\section{Introduction}

The concept of Emotional Intelligence (EI) and how it influences employees' performance in service industry have gained substantial attention from researchers. Daniel Goleman's (1998) first article, published in Harvard Business Review on EI and leadership, "What Makes a Leader?", discussed five components of EI at work, i.e. Self-Awareness, Self-Regulation, Motivation, Empathy and Social skills. He found that EI has direct ties or links with business results and it is well worth consideration of individuals as well as organizations. He agreed that the process is not easy and it takes time. EI can be developed within an organization as a part of strategic and tactical management plan to achieve ultimate success. It can improve employees' performance, in terms of increased productivity and emotional attachment. Cherniss (2000) found that EI can improve productivity and psychological well-being in the workplace of tomorrow.

The strategic management and EI both start from top level of management and they trickle down the hierarchy. As strategic management formulates and implements tactics, it tries to match organizational resources with long term objectives. It addresses long term vision of organization, and accordingly operational strategies are worked out. According to Kodama (2006), strategy framework enables companies to continuously evolve the creation and construction of a new market position, and acquire new capabilities with the aim of achieving innovations for the future. On the contrary, operational strategy focuses on operational contents and processes, which provide directions and actions in sustaining current competitive advantages. 
To evaluate the impact of EI on employees and customers, and its bearing on Operational Efficiency (OE), the present authors felt a need to examine the stimulus of EI on Employees Satisfaction (ES), Employees Loyalty (EL), Costumers Satisfaction (CS), Customers Loyalty (CL) and Operation Efficiency (OE), with special reference to telecom service industry in Oman. Towards this end, the following Research Questions (RQs) were posed for this study:

RQ1: Does EI influence ES and EL?

RQ2: Do ES and EL have any bearing on CS and CL?

RQ3: Do CS and CL provide stimulus to OE in telecom service industry?

Services offered by Original Equipment Manufacturers (OEMs), Telecom Service Providers (TSPs) and End Users (EUs) were included in this research. OEMs' services include telecom and infrastructure, whereas TSPs services are considered as voice, data, lease line and other miscellaneous Value Added Services (VAS). Subsequently, the objectives of the study were extended to empirically investigate the following relationships:

a. Influence of EI on ES and EL

b. Impact of EL on Service Quality (SQ), CL and productivity

c. Bearing of CL, Service Values, Productivity on OE, and

d. How OE further consolidates ES and EL.

\section{Theoretical Background}

The relationship of ES, EL and its impact on service quality (SQ) is still shrouded in uncertainties. It remains a cross-disciplinary subject straddling human resources, operation and strategic management domains. The present study evaluated the impact of EI on ES and EL; they get later translated into SQ, which in turn undergoes transformation into Productivity and OE. How does the improved OE further consolidate ES and EL? Sureshchandar, Rajendran, \& Anantharaman (2002) found that the relationship between SQ and CS constructs are indeed independent, yet are closely related, implying that an increase in one is likely to increase the other.

In a competitive market, service companies have to offer not only services at competitive price but also complete solutions to minimize churn. Service values have to be enhanced based on clear understanding of the customers' requirements, expectations, and perception of service with respect to its price. According to Vo and Nguyen (2015), the perceived service quality directly influences consumers' purchase intention or decision. The SQ and service values remain the key attributes of service performance and customers' repurchase behavior.

The Service Profit Chain (SPC) framework published by Heskett, Jones, Sasser, and Schlesinger (1994) establishes relationships between ES, EL, CS, CL, and Firm's Profitability (FP) in a service industry. SPC provides an integrated framework on service operations, customers' perceptions and 78ehavior, and how these attributes translate into profits. The links are regarded as propositions that 'promote' ES to bring in high quality support services, which enable employees to deliver outcomes to the customers; they in turn bring customer loyalty, profitability and growth for service industry.

In the context of the foregoing, the present researchers were motivated to empirically validate this inter-linkage or inter-relationship, since no such studies were conducted by keeping the complete service chain in view. Services are rendered by OEMs to TSPs, and subsequently services flow from TSPs to Eus. Hence, it has been decided to collect data from all these three sources, viz. OEM, TSP and EU. However, there exist a few research works on conceptual framework that empirically validated on single source of data, i.e., either from TSPs or Eus only, or in some cases, from just a combination of TSPs and Eus only. On the other hand, the present study takes into account all the three stakeholders or players in the framework (OEM, TSP and EU) for a comprehensive study.

Accordingly, having provided some theoretical background to this study, the present paper proceeds to introduce the conceptual model, formulate working hypotheses and methodologies, and finally these hypotheses were tested using Statistical Package for the Social Science (SPSS) software package with collected empirical data. The results of the research are then discussed, along with its limitations and scope for future research.

\section{Conceptual Model and Hypotheses Development}

\subsection{Conceptual Model}

A conceptual model was developed based on RQs and objectives of the study. The model, as shown in Figure 1, demonstrates the links and flows of internal performance, and impacts of internal performance on service values, which in turn yield Operational Efficiency; this OE is then fed back into the internal performance processes, 
thereby completing the cycle. Figure 1 depicts the conceptual model for this study.

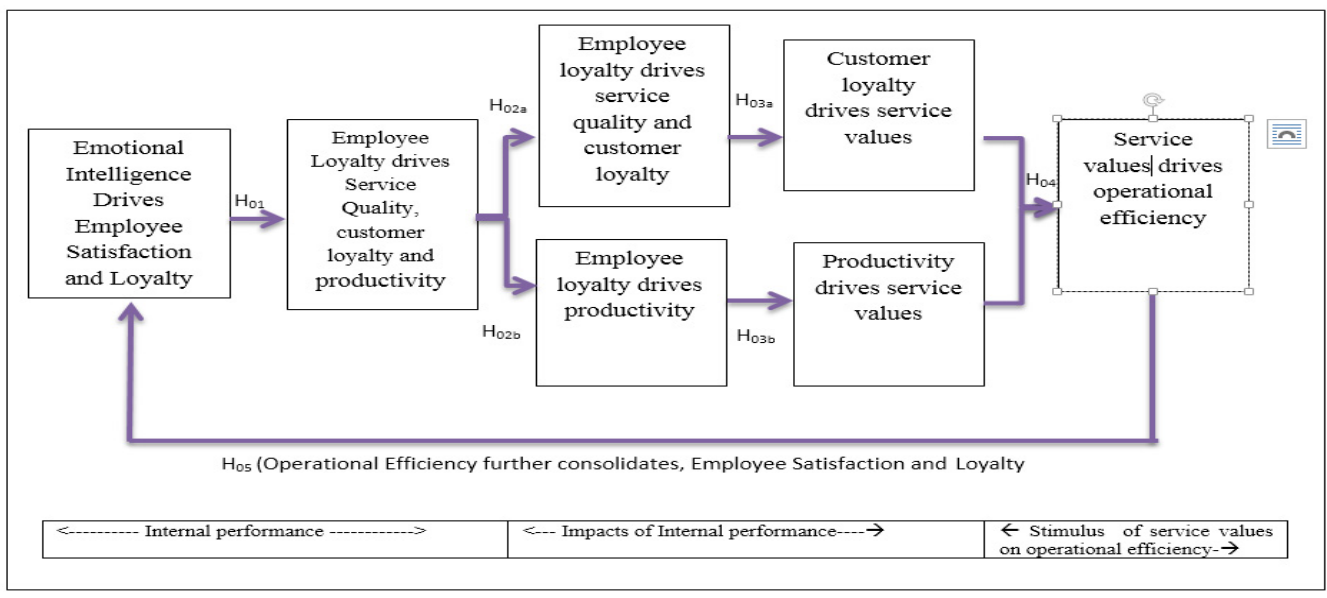

Figure 1. Conceptual model

\subsection{Internal Performance}

EI drives ES and EL: The behavior of EI brings forth positive effects in building relationship and gaining emotional commitment of employees. It creates effective communication with employees, develops trust, and increases synergy between employees and management. Goleman \& Boyatzis (2008) found that there is a large performance gap between socially intelligent and socially unintelligent leaders. EI puts importance on self-development of leaders and leadership qualities. An effective leadership will always emphasize on internal SQ within the organization to positively influence the employees.

ES has attracted researcher's attention and it remains an important factor for service industries for maintaining and enhancing CS and CL. According to Heskett et al., (1994) internal SQ of working environment contributes most to employee satisfaction, which is measured by employees' feeling towards their job, colleagues and the company.

The factors contributing to ES are organizational culture, quality of work life, working environment, human resource practices, work design model, and values practiced by the company. It supports and promotes the idea that employees are human capital and shall be treated well, e.g. by way of giving due recognition and importance. The idea of creating a supportive internal environment with the aim of improving ES and EL is, of course, to enhance productivity and profitability of the company.

In addition to Heskett, other researchers too have explored the concept of internal SQ and proposed that awareness of supportive work environments be created. Little (2006) found that service climate in an organization, as perceived by employees, is positively related to SQ, as perceived by customers. Hence, employees should be viewed as an organisation's most valuable asset, and they shall be rightfully treated in order to gain competitive advantage. According to (Bellou 2008), internal SQ positively and effectively improved SQ provided to customers and hence their satisfaction. Accordingly, following hypotheses are discussed that:

\section{$H_{01}:$ EI drives ES and EL.}

EL drives SQ, CL and productivity: The terms ES and EL have been used in operations and human resource management for a long time. And with the globalization of economy, it has become a buzz word for the service industry. The satisfied and loyal employees put their best effort to improve SQ and customer relationship. Theoharakis (2009) found that satisfied and loyal employees are better in developing relationships with customers and strategic partners. EL is an important variable that expresses the feeling and thinking of employees regarding current job as against the opportunities existing outside of company. As loyalty with employer increases, it proportionately increases satisfaction and vice versa.

ES can also be referred to as job satisfaction. It combines emotional reactions and differential perceptions of what employees want to receive as compared to what is actually received. On the other hand, from employees' 
perspective, it is the current job and approach towards the job that lead to EL and retention. Wisner (2005) found that satisfied volunteers are more likely to remain for longer periods of time with the same organization, donate financially, and recommend the volunteer experience to others. ES and EL remained for long a challenge, and they are now critical for the industry to compete globally in terms of improving SQ and OE. The improvement in SQ comes from the initiatives of employees and their innovative ideas, which in turn add values that have a bearing on CS and CL. Improved ES and EL are likely to enhance SQ, productivity, customers' retention and profitability. Accordingly, it is proposed that:

\section{$H_{02 a}: E L$ has a positive impact on $S Q$ and $C L$.}

$H_{02 b}:$ EL has a positive impact on productivity.

\subsection{Impact of Internal Performance}

CL and productivity have positive impact on service values: The service values are the processes that are followed in the service delivery system. It is a relative function with respect to customers' perception of service and results obtained for the price paid. On the contrary, service values from organization's point of view are the service cost and the benefits derived by the customers. The service provider should know service values in terms of its worth, and accordingly services are priced. Customers develop brand loyalty based on the perceived service values. According to Ahmad \& Sherwani (2015), brand loyalty can be increased when the customer is aware of the brand's good image and better quality.

The service delivery system is an output from service industry in offering services to the customers. As its efficiency increases, it paybacks to the customers, in terms of improved SQ and service values. The service values reside exclusively in customers' perception of quality and services received. Proper service values will have positive association with CS. Usually, companies evaluate service values through improved CS, repurchase behaviour, and positive word of mouth. Therefore, it is possible that customers' perception of SQ may be low, but still they are satisfied because of low cost. It can lead to a notion that service values are the better indicators of CS in service industry. Johnston (1999) found that improvement in quality, performance and design help develop the subject of service management.

In the competitive market, it is important to know how an organization manages its employees, customers and the technological advancement. Therefore, not only the SQ and productivity determine CS, but service values also contribute to a great extent, which remains key concept in service delivery system. Therefore, the following hypotheses were proposed:

\section{$H_{03 a}: C L$ has a positive impact on service values.}

$H_{03 b}$ : Productivity has a positive impact on service values.

\subsection{Stimulus of Service Values on Operational Efficiency}

Service values and operational efficiency: ES and EL increase SQ, productivity and service delivery system. Improved SQ facilitates greater service values to customers, which in turn, increase CS and CL. It further strengthens the relationship between customers and the service provider and later that becomes significant driver for CL. The loyal customers consolidate their commitment, and with time become brand ambassadors. Duffy (2003) found that CL yields significant benefits in overall business strategy. It leads to commitment that reduces disappointment and encourages customers to continue with existing service provider.

The improved service values would increase CS, repurchase 80ehavior, and loyalty. Long term association leads to customers' commitment, contentment, and un-intentional captivity with the service provider. Rowley (2005) found that there are four types of loyal customers: captive, convenience-seeker, contended and committed. The different categories will respond differently in their 80ehavior, and attitudes to switching. Contended and committed customers would be loyal, and share their positive feedback with others.

Hence, it is essential to take care of loyal customers since they are going to continue with the company. These customers likely to spread positive word of mouth, make repeat purchases that will increase revenue and profitability. The companies need to put greater attention for enhancing productivity and profitability. Improved productivity would further increase retention and loyalty, and minimize churn. Van, Tuan, Hoang, Minh, (2016) found that due to rigorous competition, not only acquiring new customer is becoming difficult but holding existing customers also turns out to be a challenging task. Therefore CL can be achieved by meeting customers' perception of service and values obtained for the price paid. Accordingly, one can posit that:

\section{$H_{04}:$ Service value has a positive impact on Operational Efficiency.}

Operational efficiency enhances ES and EL: The essential management ingredients are to develop employees' 
confidence, and keep them satisfied and loyal, for realization of service values. In general, management teams, and particularly senior management's active involvement, is essential for achieving ES and EL and for eventually obtaining CS and CL. It would ultimately lead to an upsurge in revenues, profitability and OE.

An improved OE would positively reduce operating cost, and increase margin and profitability. The OE can be enhanced by instilling the concept of service values among the employees, who would put their best foot forward to improve SQ, CS, CL and productivity. Improved satisfaction and loyalty shall spread positive word of mouth. Improved $\mathrm{OE}$ enhances profitability, which is generally shared by owner, employees, and other stakeholders, leading eventually to enhance in ES and EL. Therefore, the employer should take care of employees and a service company to make conscious efforts for it. Heskett et al. (1994) found that highly satisfied customers drive growth and profitability in service businesses, and to keep them profitable, manage SPC. Accordingly, it was predicted that:

\section{$H_{05}$ : Operational Efficiency further consolidates Employee Satisfaction and Employee Loyalty.}

\section{Methodologies}

The selection and design of questionnaires were based on RQs, objectives and hypotheses as formulated above. Accordingly, samples were collected from all strata of the population. All possible efforts were made to collect samples from all the target groups i.e. from OEMs, TSPs and EUs. It is estimated that cumulative employee strength of OEMs and TSPs were 600 and 4,400 respectively, and the number of EUs, who use one or more services, were approximately 2 million out of the total population of 3.5 million (in Oman). The remaining 1.5 million were considered to be children and the aged who may not be an active user. OEMs and TSPs surveys were conducted by one of the authors, whereas for EUs questionnaire survey, the assistance of friends, family members and students were enlisted.

Convenience sampling method was used, giving unique identification number for each element. The sample sizes were well drawn from the entire country, representing the whole population. All possible measures were taken to capture samples from entire population. However, there might be some possibility that some elements were overlooked. Table 1 summarises target segments, population size, sample size for each segment along with, questionnaire administered, retrieved, and response rate:

Table 1. Target segments, population, sample size, administered and retrieved questionnaires

\begin{tabular}{llllll}
\hline $\begin{array}{l}\text { Target } \\
\text { Segments }\end{array}$ & Population Size & Proposed Sample Size & Questionnaires Administered & $\begin{array}{l}\text { Retrieved } \\
\text { Questionnaires }\end{array}$ & Response Rate \\
\hline OEMs & 600 & 60 & 100 & 66 & $66 \%$ \\
SPs & 4,400 & 176 & 350 & 201 & $57 \%$ \\
EUs & $2,000,000$ & 600 & 1,000 & 621 & $62 \%$ \\
Total & $2,005,000$ & 836 & 1,450 & 888 & $61 \%$ \\
\hline
\end{tabular}

It was proposed to collect a minimum of 60 (Yee, Yeung, \& Cheng, 2011), 176 (Hadi, 2015) and 600 (Homburg, Wieseke \& Hoyer, 2008) samples from OEMs, TSP, and Eus respectively. Yee, Yeung, \& Cheng, (2011) found that a sample size of 45 from agency services was considered adequate for their research. Accordingly, in this study, assuming OEMs function as agency services, the present researchers decided to take a minimum of 60 samples.

\section{Variables of the Study}

Data were collected from OEMs, TSPs and EUs on their various attributes. Appropriate abbreviations and suitable subscripts were assigned to each source of data to distinguish data of different sources. For example, data on OEMs' employee satisfaction $\left(\mathrm{ES}_{\mathrm{M}}\right)$, employee loyalty $\left(\mathrm{EL}_{\mathrm{M}}\right)$, service quality $\left(\mathrm{SQ}_{\mathrm{M}}\right)$, sales from repurchase and referrals $\left(\mathrm{SR}_{\mathrm{M}}\right)$ and firm's profitability $\left(\mathrm{FP}_{\mathrm{M}}\right)$ were defined. Here $\mathrm{SQ}_{\mathrm{M}}$ indicates OEM's perception of SQ received by TSPs, and $\mathrm{SR}_{\mathrm{M}}$ stands for OEM's perception of their sale from repurchase and referrals based on TSPs' recommendations.

Similarly, the TSPs' data comprised ES $\left(\mathrm{ES}_{\mathrm{S}}\right)$, EL $\left(\mathrm{EL}_{\mathrm{S}}\right), \mathrm{SQ}\left(\mathrm{SQ}_{\mathrm{S}}\right)$, sales from repurchase and referrals $\left(\mathrm{SR}_{\mathrm{S}}\right)$, and firm's profitability $\left(\mathrm{FP}_{\mathrm{S}}\right)$. Here $\mathrm{SQ}_{\mathrm{S}}$ represented two sets of data i.e. TSPs' opinion of SQ offered by OEMs and their perception of SQ delivered to the Eus. Likewise, $\mathrm{SR}_{\mathrm{S}}$ represents two sets of data i.e. TSPs' repurchase intention of services from the OEMs and TSPs' perceptions of Eus' repurchase intentions with TSPs.

In the same way, the Eus data include Eus' view on $\mathrm{SQ}\left(\mathrm{SQ}_{\mathrm{EU}}\right), \mathrm{CL}\left(\mathrm{CL}_{\mathrm{EU}}\right)$, and repurchase intention and 
positive word of mouth $\left(\mathrm{SR}_{\mathrm{EU}}\right)$ for TSP, which signifies $\mathrm{EU}_{\mathrm{S}}$ ' intentions of repurchase and referrals.

\section{Analysis and Results}

An empirical study was conducted to test these hypotheses in the context of a telecom service industry. While designing questionnaires, special attention was given to obtain forward and backward feedback from TSPs on SQ and SRs. The data were screened through three different tests, i.e. descriptive properties, combined correlation matrix test and validation of null hypotheses.

\subsection{Descriptive Properties of Variables for OEMs, TSPs and EUs}

Table 2 represents descriptive properties of selected variables from OEMs, TSPs and EUs, where $\mathrm{SQ}_{\mathrm{M}}$, has the highest mean value, lowest standard deviation and highest value of Cronbach's alpha. It means that $\mathrm{SQ}_{\mathrm{M}}$ has significant impact on service delivery system, i.e. service delivered from OEMs to TSPs to EUs. It is obvious that once OMEs' services are of high standard, TSPs and EUs are naturally would be pleased and satisfied.

Similarly, other high mean values for $\mathrm{EL}_{\mathrm{S}}$ and $\mathrm{FP}_{\mathrm{S}}$ can be interpreted this way: once $\mathrm{EL}_{\mathrm{S}}$ grows, firm profitability will also grow; loyal employees are more likely to attend to customers, develop better relationship and provide better services. Theoharakis (2009) found that satisfied and loyal employees are better in developing relationships with customers and strategic partners, which increase CS and CL and ultimately financial performance.

Table 2. Descriptive properties for OEMs, TSPs and EUs

\begin{tabular}{lllll}
\hline $\mathrm{SN}$ & Variables & Mean & Standard deviation & Cronbach's alpha \\
\hline 1 & $\mathrm{ES}_{\mathrm{M}}$ & 3.30 & 0.669 & 0.81 \\
2 & $\mathrm{EL}_{\mathrm{M}}$ & 3.29 & 0.904 & 0.91 \\
3 & $\mathrm{SQ}_{\mathrm{M}}$ & 3.84 & 0.569 & 0.82 \\
4 & $\mathrm{SR}_{\mathrm{M}}$ & 3.37 & 0.613 & 0.79 \\
5 & $\mathrm{FP}_{\mathrm{M}}$ & 3.43 & 0.698 & 0.91 \\
6 & $\mathrm{ES}_{\mathrm{S}}$ & 3.14 & 0.736 & 0.69 \\
7 & $\mathrm{EL}_{\mathrm{S}}$ & 3.53 & 0.712 & 0.71 \\
8 & $\mathrm{SQ}_{\mathrm{S}}$ & 3.41 & 0.674 & 0.74 \\
9 & $\mathrm{SR}_{\mathrm{S}}$ & 3.40 & 0.589 & 0.39 \\
10 & $\mathrm{FP}_{\mathrm{S}}$ & 3.52 & 0.627 & 0.79 \\
11 & $\mathrm{SQ}_{\mathrm{EU}}$ & 3.36 & 0.721 & 0.699 \\
12 & $\mathrm{CL}_{\mathrm{EU}}$ & 3.27 & 0.370 & 0.736 \\
13 & $\mathrm{SR}_{\mathrm{EU}}$ & 3.24 & 0.796 & 0.736 \\
\hline
\end{tabular}

The reliability of sub-scale parameters is determined by Cronbach's alpha. Values of Cronbach's alpha for all variables have high degree of reliability, i.e. $\alpha>0.6$, except for $\mathrm{SR}_{\mathrm{s}}=0.39$. The highest value is $\alpha>=0.91$ for $\mathrm{EL}_{\mathrm{M}}$ and $\mathrm{FP}_{\mathrm{M}}$, which shows that these variables have an excellent high stake consistency. Hence, $\mathrm{EL}_{\mathrm{M}}$ drives growth and profitability due to engaged employees. Slatten (2011) found that employee engagement is closely linked to employees' innovative behaviour-

The Cronbach's alpha for $\mathrm{SR}_{\mathrm{S}}=0.39$ indicates that even though customers are satisfied and loyal, they may not repurchase services due to multiple available options. Mobile Number Portability (MNP) facility being the norm these days with many service providers, EUs find it easy to switch to other carriers without changing their numbers. These observations affirm that ES and EL lead to higher operational efficiency.

\subsection{Combined Correlation Analysis of OEMs', TSPs' and EUs' Variables}

Correlation analysis was carried out after removing inconsistent and invalid responses. The final retrieved questionnaires were 66, 201 and 621 from OEMs, TSPs, and EUs respectively. In the combined correlation matrix, all 66 samples of OEMs were considered, whereas 66 samples from TSPs and EUs were randomly selected with the aim of including data of all the attributes and segments. Selected variables from OEMs, TSPs and EUs are:

- EL from OEMs and TSPs to find and to evaluate whether internal SQ is in line with employees' expectations and satisfaction, and is in accordance with company policies.

- Sales from repurchase and referrals from OEMs and TSPs to find whether TSPs are willing to repurchase and refer OEMs' services to others. Similarly, TSPs' sales from repurchase and referrals are considered to gauge EUs repurchase intentions and their willingness to refer TSPs' services to others. 
- $\mathrm{SQ}_{\mathrm{EU}}$ and $\mathrm{CL}_{\mathrm{EL}}$ data are considered to be a measure of SQ as perceived by EUs and their loyalty with TSPs

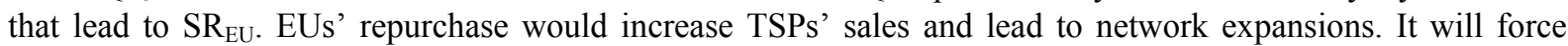
TSPs to repurchase equipment and services from OEMs. The chain of repurchase actions from EUs to TSPs and from TSPs to OEMs would improve financial position and OE of TSPs and OEMs.

The Table 3 shows combined correlation matrix, positively and significantly correlated 0.01 levels (2-tailed). It conforms to the inter-relationships among selected variables as explained earlier. The variables like $\mathrm{EL}_{\mathrm{M}}, \mathrm{SR}_{\mathrm{M}}$, $\mathrm{EL}_{\mathrm{S}}$ and $\mathrm{SR}_{\mathrm{S}}, \mathrm{CS}_{\mathrm{EU}}$ and $\mathrm{CL}_{\mathrm{EU}}$ represent comprehensive service chain relationships.

Table 3. Combined correlation analysis of OEMs, TSPs and EUs

\begin{tabular}{|c|c|c|c|c|c|c|c|}
\hline & & $E L_{M}$ & $\mathrm{SR}_{\mathrm{M}}$ & $\mathrm{EL}_{\mathrm{S}}$ & $\mathrm{SR}_{\mathrm{S}}$ & $\mathrm{CS}_{\mathrm{EU}}$ & $\mathrm{CL}_{\mathrm{EU}}$ \\
\hline \multirow[t]{3}{*}{$\mathrm{EL}_{\mathrm{M}}$} & Pearson Correlation & 1 & 0.060 & 0.028 & -0.033 & 0.062 & 0.036 \\
\hline & Sig (2-tailed) & & 0.634 & 0.824 & 0.791 & 0.619 & 0.775 \\
\hline & $\mathrm{N}$ & 66 & 66 & 66 & 66 & 66 & 66 \\
\hline \multirow[t]{3}{*}{$\mathrm{SR}_{\mathrm{M}}$} & Pearson Correlation & & 1 & $0.475^{* *}$ & 0.063 & 0.135 & 0.012 \\
\hline & Sig (2-tailed) & & & 0.000 & 0.614 & 0.279 & 0.922 \\
\hline & $\mathrm{N}$ & & 66 & 66 & 66 & 66 & 66 \\
\hline \multirow[t]{3}{*}{$\mathrm{EL}_{\mathrm{S}}$} & Pearson Correlation & & & 1 & 0.021 & 0.178 & 0.024 \\
\hline & Sig (2-tailed) & & & & 0.868 & 0.152 & 0.847 \\
\hline & $\mathrm{N}$ & & & 66 & 66 & 66 & 66 \\
\hline \multirow[t]{3}{*}{$\mathrm{SR}_{\mathrm{S}}$} & Pearson Correlation & & & & 1 & $0.680^{* *}$ & $0.799 * *$ \\
\hline & Sig (2-tailed) & & & & & 0.000 & 0.000 \\
\hline & $\mathrm{N}$ & & & & 66 & 66 & 66 \\
\hline \multirow[t]{3}{*}{$\mathrm{CS}_{\mathrm{EU}}$} & Pearson Correlation & & & & & 1 & $0.724 * *$ \\
\hline & Sig (2-tailed) & & & & & & 0.000 \\
\hline & $\mathrm{N}$ & & & & & 66 & 66 \\
\hline \multirow[t]{3}{*}{$\mathrm{CL}_{\mathrm{EU}}$} & Pearson Correlation & & & & & & 1 \\
\hline & Sig (2-tailed) & & & & & & \\
\hline & $\mathrm{N}$ & & & & & & 66 \\
\hline
\end{tabular}

The combined correlation co-efficient for $\mathrm{SR}_{\mathrm{S}}$ and $\mathrm{CL}_{\mathrm{EU}}=0.799$ shows that EUs' loyalty would lead to repurchase and referrals of TSPs' services. The other strong correlations were found between $\mathrm{CS}_{\mathrm{EU}}$ and $\mathrm{CL}_{\mathrm{EU}}$, $\mathrm{SR}_{\mathrm{S}}$ and $\mathrm{CS}_{\mathrm{EU}}$, which can be interpreted as indicating that Eus' satisfaction will lead to loyalty and repurchase.

Correlation co-efficient for $\mathrm{EL}_{\mathrm{M}}$ and $\mathrm{SR}_{\mathrm{S}}$ is marginally negative and insignificant. It might be due to the fact that data were collected from two different sources and it was obvious that $\mathrm{EL}_{\mathrm{M}}$ should not influence $\mathrm{SR}_{\mathrm{S}}$. The combined correlations matrices show that all the variables are significantly correlated to each other. The inter-relationships among CS, CL and SR are in accordance with the assumptions made.

\section{Testing of the Null Hypotheses}

Testing and verification of null hypotheses were accomplished by authenticating the relationships and linkages between various parameters by using ordinary least squares (OLS) regression and analysis of variance (ANOVA).

ES drives $\boldsymbol{E L}$ : To validate this hypothesis, the OEMs and TSPs data on ES and EL were used. Null hypothesis was tested by using OLS regression to find unknown parameters of dependent variables for measuring how ES $_{M}$ and $\mathrm{ES}_{\mathrm{S}}$ influence $\mathrm{EL}_{\mathrm{M}}$ and $\mathrm{EL}_{\mathrm{S}}$ respectively. With $\mathrm{EL}_{\mathrm{M}}$ as a dependent and $\mathrm{ES}_{\mathrm{M}}$ as an independent variable, one arrives at the following relations:

$$
\begin{aligned}
\mathrm{EL}_{\mathrm{M}} & =0.338+0.895 * \mathrm{ES}_{\mathrm{M}} \\
\mathrm{EL}_{\mathrm{S}} & =1.442+0.666 * \mathrm{ES}_{\mathrm{S}}
\end{aligned}
$$

Table 4. OEMs' null hypothesis results using OLS regression

\begin{tabular}{cccccccccc}
\hline \multirow{2}{*}{ Model } & \multirow{2}{*}{$\mathrm{R}$} & \multirow{2}{*}{$\mathrm{R}^{2}$} & Adjusted & \multicolumn{3}{c}{ Coefficients } & \multicolumn{3}{c}{ ANOVA } \\
\cline { 5 - 9 } & & & $\mathrm{R}^{2}$ & Const & $\mathrm{ES}_{\mathrm{M}}$ & $\mathrm{t}$ value & Sig. & F value & Sig. \\
\hline $\mathrm{EL}_{\mathrm{M}}$ & 0.662 & 0.438 & 0.429 & 0.338 & 0.895 & 0.793 & 0.431 & 7.060 & 0.000 \\
$\mathrm{EL}_{\mathrm{S}}$ & 0.689 & 0.475 & 0.472 & 1.443 & 0.666 & 9.008 & 0.000 & 13.410 & 0.000 \\
\hline
\end{tabular}


Table 4 summarises null hypothesis results, which were examined through appropriate statistical instruments. It was found that the relationship between $\mathrm{ES}_{\mathrm{M}}$ and $\mathrm{EL}_{\mathrm{M}}$ is unbiased. Value of adjusted $\mathrm{R}^{2}=42.9 \%$, and $\mathrm{ES}_{\mathrm{M}}$ co-efficient $=0.895$, which is interpreted to mean that a unit change in $\mathrm{ES}_{\mathrm{M}}$ will have an impact of 0.895 on $\mathrm{EL}_{\mathrm{M}}$. The path model between $\mathrm{ES}_{\mathrm{M}}$ and $\mathrm{EL}_{\mathrm{M}}$ is well linked with a global fit value (Adjusted $\mathrm{R}^{2}=0.429, \mathrm{t}=0.793$, $\mathrm{F}=7.060$ at $\mathrm{p}=0.000$ ). It signifies that the model is acceptable and compatible with the empirical data. The high value for $\mathrm{ES}_{\mathrm{M}}$ is because of increased $\mathrm{EL}$, and this may be due to employees' motivation, job satisfaction and organizational culture. Bloemer \& Schroder (2006) found that there are potential connections between organizational culture, and employee satisfaction, identity, mood, creativity and motivation, hence the above relationships (1) and (2).

Similar relationships were found between $\mathrm{ES}_{\mathrm{S}}$ and $\mathrm{EL}_{\mathrm{S}}$, which were well linked with global fit of values (Adjusted $\mathrm{R}^{2}=0.472, \mathrm{t}=9.008, \mathrm{~F}=13.410$ at $\mathrm{p}=0.000$ ). These values are found to be significant and the model fits acceptably well with empirical data. The result shows that $\mathrm{ES}_{\mathrm{S}}$ will have positive impact of 0.666 on $\mathrm{EL}_{\mathrm{S}}$, i.e. once employees are satisfied they will remain loyal.

These results support the hypothesis $\left(\mathrm{H}_{01}\right)$ that emotional intelligence drives employee satisfaction and loyalty. The findings are in agreement with other researchers, such as (Schlesinger \& Heskett, 1991). Satisfied employees will equate to highly loyal employees, which will lead to increased CL, and eventually will improve business performance. Accordingly, the following two hypotheses can be derived:

\section{$H_{01}$ : Emotional Intelligence has strong and positive effects on ES and EL.}

\section{$H_{02}: E L$ drives $S Q, C L$ and productivity-}

The relationship between $\mathrm{EL}_{\mathrm{M}}$ and $\mathrm{SQ}_{\mathrm{M}}$ was tested on data collected from OEMs in which $\mathrm{SQ}_{\mathrm{M}}$ was related to TSPs' views on SQ . Bunyaminu \& Quansah (2015) found that CS survey depends less on the opinion of the employees on SQ. Hence, TSPs' views were taken instead of employees of OEMs' feedback on SQ $\mathrm{M}_{\mathrm{M}}$. The null hypothesis was tested to find how $\mathrm{EL}_{\mathrm{M}}$ influences $\mathrm{SQ}_{\mathrm{M}}$. With $\mathrm{SQ}_{\mathrm{M}}$ as a dependent and $\mathrm{EL}_{\mathrm{M}}$ as an independent variable, this relation is derived:

$$
\mathrm{SQ}_{\mathrm{M}}=2.578+0.383 * \mathrm{EL}_{\mathrm{M}}
$$

The relationship between $\mathrm{SQ}_{\mathrm{M}}$ and $\mathrm{EL}_{\mathrm{M}}$ reveals an unbiased result, with an adjusted value of $\mathrm{R}^{2}=36.1 \%$, and $\mathrm{EL}_{\mathrm{M}}$ co-efficient $=0.383$. The path model for $\mathrm{EL}_{\mathrm{M}}$ and $\mathrm{SQ}_{\mathrm{M}}$ is well linked with global fit values (Adjusted $\mathrm{R}^{2}$ $=0.361, \mathrm{t}=12.107, \mathrm{~F}=6.139$ at $\mathrm{p}=0.000$ ), which is significant and the model acceptably fits with empirical data. The result shows that an increase in $\mathrm{EL}_{\mathrm{M}}$ will have positive impact of 0.383 on $\mathrm{SQ}_{\mathrm{M}}$. The increased $\mathrm{SQ}_{\mathrm{M}}$ will reduce wastage of materials, rework and minimize human efforts, and these will positively impact on productivity. The result shows that $\mathrm{EL}_{\mathrm{M}}$ drives $\mathrm{SQ}_{\mathrm{M}}$ and productivity that will give better brand positioning. Shen (2015) found that among corporate strategies, brand positioning remains the key strategy that paves the way for success.

Similarly, null hypothesis was tested for TSPs to find the stimulus of $\mathrm{EL}_{S}$ on $\mathrm{SQ}_{\mathrm{S}}$, in which $\mathrm{SQ}_{\mathrm{S}}$ was considered as a dependent and $\mathrm{EL}_{\mathrm{S}}$ as an independent variable, where $\mathrm{SQ}_{\mathrm{S}}$ relates to $\mathrm{EU}_{\mathrm{S}}$ ' view of $\mathrm{SQ}_{\mathrm{S}}$, leading to the following relation:

$$
\mathrm{SQ}_{\mathrm{S}}=1.856+0.440 * \mathrm{EL}_{\mathrm{S}}
$$

The path model between $\mathrm{EL}_{\mathrm{S}}$ and $\mathrm{SQ}_{\mathrm{S}}$ was well linked, with global fit values of adjusted $\mathrm{R}^{2}=0.212, \mathrm{t}=8.661$, $\mathrm{F}=7.409$ at $\mathrm{p}=0.000, \mathrm{EL}_{\mathrm{S}}=0.440$, which was significant and acceptably fits with empirical data. The result shows that $\mathrm{EL}_{\mathrm{S}}$ will have positive impact of 0.440 on $\mathrm{SQ}_{\mathrm{S}}$. Hence, it is inferred that $\mathrm{SQ}_{\mathrm{S}}$ can be improved through employees' contribution, participation and involvement, and it can be achieved only by satisfied and loyal employees. Accordingly, it is assumed that:

\section{$H_{02 a}: E L$ has a positive impact on $S Q$ and $C L$}

\section{$H_{02 b}:$ EL has a positive impact on productivity}

\section{$H_{03}: C L$ and productivity drive service values:}

This relationship was tested on the data collected from OEMs on their insight of $\mathrm{CL}_{\mathrm{M}}$ and $\mathrm{SR}_{\mathrm{M}}$ in improving productivity and increased sales. Null hypothesis was tested to find the relationship by considering $\mathrm{SR}_{\mathrm{M}}$ as a dependent and $\mathrm{CL}_{\mathrm{M}}$ as an independent variable, thus arriving at this relation:

$$
\mathrm{SR}_{\mathrm{M}}=0.730+0.772 * \mathrm{CL}_{\mathrm{M}}
$$

The path model for $\mathrm{CL}_{\mathrm{M}}$ and $\mathrm{SR}_{\mathrm{M}}$ is significant, well linked and acceptably fits with global values (Adjusted $\mathrm{R}^{2}=0.503, \mathrm{t}=2.226, \mathrm{~F}=8.167$, at $\mathrm{p}=0.000$ ). The result shows that $\mathrm{CL}_{\mathrm{M}}$ will increase $\mathrm{SR}_{\mathrm{M}}$, which is due to 
increased service values and productivity. The $\mathrm{CL}_{\mathrm{M}}$ co-efficient being 0.772 , it demonstrates well that an increase in $\mathrm{CL}_{\mathrm{M}}$ will have positive impact on repurchase and referrals. Therefore, OEMs should undertake technological upgrades to satisfy TSPs' and to meet EUs' expectations. The virtual service value chain, such as value added services like video streaming, reliable broadband, m-commerce, and e-commerce, could assist in managing business electronically. Bhatt \& Emadad (2001) found that in e-commerce, more and more value chain activities are conducted electronically, and therefore businesses should understand the implication of the virtual value chain activities.

Similarly, null hypothesis was tested for TSPs to find the relationship between $\mathrm{CL}_{\mathrm{S}}$, productivity and service value in terms of increase in sales. TSPs data were used on EUs' loyalty and repurchase intentions. Considering $\mathrm{SR}_{\mathrm{S}}$ as a dependent and $\mathrm{CL}_{\mathrm{S}}$ as an independent variable, one gets the following relation:

$$
\text { SRs }=0.558+0.848 * \text { CLs }
$$

The derived results are unbiased and path model between $\mathrm{CL}_{\mathrm{S}}$ and $\mathrm{SR}_{\mathrm{S}}$ is well linked with global fit values of adjusted $\mathrm{R}^{2}=0.540, \mathrm{t}=2.983, \mathrm{~F}=15.361$, at $\mathrm{p}=0.000, \mathrm{CL}_{\mathrm{S}}=84.8$, which is significant and the model acceptably fits with empirical data. The result shows that EUs' loyalty will have positive impact on sales from repurchase and referrals. Felix (2015) found that high CS leads to strengthening of the relationship between customers and a company, and a deep sense of collaboration is found to be profitable. Increased sales would be due to repurchases and referrals. It will improve margin, profit, and lower operating and customer acquisition cost. Therefore, loyal customers will repurchase services, and will become brand ambassadors, by recommending their experience to others and acknowledging service values. Accordingly, it is proposed that:

\section{$H_{03 a}:$ Customer Loyalty has a positive impact on service value}

\section{$H_{03 b}$ : Productivity has positive impact on service value.}

Hypothesis $\boldsymbol{H}_{04}$ : Service Value and Operational Efficiency: Aghdaie, Karimi, \& Abasaltian (2015) found that there is a relationship between quality of information and customer satisfaction. Customers derive values and contentment, once they receive information on time. It leads to sales from repurchase, and positive word of mouth further increases sales and profitability. OEMs and TSPs data were used to test the null hypothesis by considering $\mathrm{FP}_{\mathrm{M}}$ as a dependent and $\mathrm{SR}_{\mathrm{M}}$ as independent variable and the following relation is obtained:

$$
\mathrm{FP}_{\mathrm{M}}=0.996+0.732 * \mathrm{SR}_{\mathrm{M}}
$$

Path model for $\mathrm{SR}_{\mathrm{M}}$ and $\mathrm{FP}_{\mathrm{M}}$ is significant and well linked with global fit values (Adjusted $\mathrm{R}^{2}=0.403, \mathrm{t}=2.580$, $\mathrm{F}=6.701$, at $\mathrm{p}=0.000$ ). The model acceptably fits with the empirical data. The $\mathrm{SR}_{\mathrm{M}}$ co-efficient 0.732 implies that $\mathrm{SR}_{\mathrm{M}}$ will have positive impact on $\mathrm{OE}$ and profitability, in which $\mathrm{SR}$ is an important factor in determining profitability. Once the company takes care of customers and keeps them satisfied, then they become loyal and the profitability grows.

Similarly, null hypothesis is tested on data collected from TSPs, by considering $\mathrm{FP}_{\mathrm{S}}$ as a dependent and $\mathrm{SR}_{\mathrm{S}}$ as independent variable and it is found that:

$$
\mathrm{FP}_{\mathrm{S}}=1.592+0.568 * \mathrm{SRs}
$$

The $\mathrm{SR}_{\mathrm{S}}$ represents exclusively employee of TSP's view on EUs' repurchase intention. The outcomes were unbiased and path model between $\mathrm{SR}_{\mathrm{S}}$ and $\mathrm{FP}_{\mathrm{S}}$ was well linked with global fit value of adjusted $\mathrm{R}^{2}=0.284$, $\mathrm{t}=7.226, \mathrm{~F}=8.226$, at $\mathrm{p}=0.000, \mathrm{SR}_{\mathrm{S}}=0.568$. It is significant and acceptably fits with empirical data. The result shows that $\mathrm{SR}_{\mathrm{S}}$ will have a positive impact on $\mathrm{OE}$ and profitability. However, it will not be linear with sales due to the fact that every sale would not earn uniform profit. At times, volume discounts or revenue sharing are offered for revenue gain. Hence, profitability would not be linear with the sale. Therefore, the empirical result shows that an increase in service values will improve sales, OE and profitability. Accordingly, it is predicted that:

\section{$H_{04}:$ Service value has positive impact on operational efficiency}

Hypothesis $\boldsymbol{H}_{05}: \boldsymbol{O E}$ and $\boldsymbol{E S}$ and $\boldsymbol{E L}$ : Researchers have intensely discussed that the parameters ES and EL are cohesively bound to each other and so inextricably intertwined that they cannot be easily separated. And, any change in one is certainly bound to impact the other. Satisfied employees equate current job with future opportunities existing within or outside of the company. With an increase in level of ES, employees are more likely to continue with their current employers.

Both ES and EL can be considered as an amalgam of characteristics like current job, pay packages, compensation, benefits, career paths, organizational policies, job nature etc. They also include relationships with supervisor, co-workers, future learning, working conditions, welfare facilities, and so on. The company retains 
profits to be shared with employees in terms of bonus, fringe benefits. Hence, an employer cannot afford to overlook these benefits. The employees should have clear idea about their career path and this would additionally contribute to the consolidation of their satisfaction and loyalty. Profitability can only be maintained subject to company taking care of employees, keeping them satisfied, and facilitating them to stay loyal. Hence, companies must give special attention to employees, and service companies, in particular, shall make distinct and deliberate efforts towards achieving both ES and EL.

In addition, the emotional states of mind would also affect employees' overall satisfaction and loyalty. Poor ES and EL will lead to high employee turnover, and will translate into higher costs, forcing the company to search for an effective way of maintaining and improving ES and EL. Accordingly, it is posited that:

\section{$H_{05}$ : Operational Efficiency has a positive impact on employee satisfaction and loyalty.}

\section{Discussion and Implications}

The present study may be characterized as an attempt to empirically validate the assumption that EI, ES and EL can act as stimuli for OE and profitability for telecom service industry in Oman. The research was carried out based on these attributes and taken through the complete chain of services from OEMs to TSPs to EUs. There have been only limited experimental studies conducted so far on these attributes in service industries, particularly in telecom services.

\subsection{Research Findings}

Lazovic (2012) has stated that EI starts from CEOs and it percolates throughout the company affecting all levels of the organisation. The EI can consolidate employees' emotion, leading to improvement in internal performance. The impact of internal performance is measured in terms of SQ, CL, and productivity. The incentives of service values are also measured in terms of higher OE, which further consolidates ES and EL. The present work thus provides the empirical evidence in support of these assumptions and hypotheses, and the inter-connected nature of the related parameters or variables.

The findings of this research also indicate that employees are valuable assets in a service industry, and growth of industry depends on employees' commitment. To maintain sustainable growth, industry shall take due care of employees, keep them satisfied, and make them remain loyal, which can be achieved through regular employees' engagement and involvement. Nadeem (2015) found that employees and corporate reputation are unique resources that contribute to positive financial performance and ultimately create sustainable competitive advantage. Engaged employees are in a better position to assess customers' expectations, which is dynamic, since customers' perceptions are ever changing with lifestyle, awareness and market conditions.

Another aspect of these findings is that service organization must work on EL, because loyal employees are highly likely to build better relationship with EUs. Satisfied and loyal employees are in a position to deliver high SQ and improved productivity. Higher productivity would improve overall OE that will definitely have a bearing on higher revenue and profitability. The increased profitability can be shared with shareholders, employees, customers by way of better promotion schemes. Higher OE would satisfy shareholders, would increase ES and EL, and would bring in captive customers.

Service provider shall continuously monitor SQ to maintain EU's satisfaction, which can be done through training and continuous development of employees' skills. Eventually, it will improve OE of the company in terms of increased sales and profitability. Finally, the present study examined how service providers manage employees' EI for gaining ES, EL, and ultimately enhancing service values, OE and profitability of the company.

\subsection{Limitations and Future Research}

The research was conducted in the context of a telecom service industry in view of its importance in today's fast changing world. Telecom is one of the essential and most sought after service by all age groups in any society. It acts like a catalyst in supporting socio-economic development, which cannot possibly happen in its absence.

It should be pointed out, in passing, that there are some limitations in this work. The questionnaires were written in English language and all possible efforts were made to use as simple a vocabulary as possible. The feedback from OEMs and TSPs was obtained by one of the researchers himself. The target groups had very good understanding of the language; hence only a few doubts were raised that were clarified immediately. However, the questionnaire for EUs was administered by friends, family and students. In some cases, respondents might not have understood the questions as a result of their limited linguistic competence in English and it is likely that surveyors were not in a position to answer some of the queries and clear their doubts. Secondly, feedback on questionnaires were collected 
using convenience sample from entire population, so it is possible that a few elements are missed out in this survey.

Future research can further explore the impact of poorly satisfied and somewhat disgruntled, but still loyal employees, who are always willing to switch to other company. The study can be further extended to test the impact of EI on complete SPC as proposed by service or production industry.

\section{Acknowledgements}

The authors are grateful to the authorities of OEMs, TSPs and EUs of Sultanate of Oman, where this research work was conducted. Thanks are also due to friends, family members and students for their contribution and untiring efforts made while collecting data from different sources.

\section{References}

Aghdaie, S. F. A., Karimi, R., \& Abasaltian, A. (2015). The Evaluation of Effect Electronic Banking in Customer Satisfaction and Loyalty. International Journal of Marketing Studies, 7(2), 90-98. http://dx.doi.org/10.5539/ijms.v7n2p90

Ahmad, F., \& Sherwani, N. U. K. (2015). An Empirical Study on the effect of Brand Equity of Mobile Phones on Customer Satisfaction. International Journal of Marketing Studies, 7(2), 59-69. http://dx.doi.org/10.5539/ijms.v7n2p59

Bellou, V., \& Andronikidis, A. (2008). Impact of Internal Service Quality on customer service behavior: Evidence from banking sector. International Journal of Quality \& Reliability Management, 25(9), 943-954. http://dx.doi.org/10.1108/02656710810908098

Bhatt, D. G., \& Emadad, A. F. (2001). An analysis of the virtual value chain in electronic commerce. Logistic Information Management, 14(1/2), 78-84. http://dx.doi.org/10.1108/09576050110362465

Bloemer, J., \& Schroder, G. O. (2006). The role of employee relationship proneness in creating employee loyalty. International Journal of Bank Marketing, 24(4), 252-264. http://dx.doi.org/10.1108/02652320610671342

Bunyaminu, A., \& Quansah, F. (2015). A Good Quality Service Provision in the Network Service in Ghana, A Case Study of MTN Ghana. International Journal of Marketing Studies, 7(3), 63-75. http://dx.doi.org/10.5539/ijms.v7n3p63

Cherniss, C. (2000). Emotional Intelligence: What it is and Why it Matters, Consortium for Research on Emotional Intelligence in Organizations. Annual Meeting of the Society for Industrial and Organizational, Psychology, New Orleans, $\quad$ LA, 2000. $\quad$ Retrieved from $\mathrm{http}: / /$ www.eiconsortium.org/pdf/what_is_emotional_intelligence.pdf

Duffy, D. L. (2003). Internal and external factors which affect customer loyalty. Journal of Consumer Marketing, 20(5), 480-485. http://dx.doi.org/10.1108/07363760310489715

Felix, E. (2015). Marketing Challenges of Satisfying Consumers Changing Expectations and Preferences in a Competitive Market. International Journal of Marketing Studies, 7(5), 41-52. http://dx.doi.org/10.5539/ijms.v7n5p41

Goleman, D. (1988). What Makes a Leader? Harvard Business Review, November-December. Retrieved from https://hbr.org/2004/01/what-makes-a-leader

Goleman, D., \& Boyatzis, R. (2008). Social Intelligence and the Biology of Leadership. Harvard Business Review, 86(9), 74-81.

Hadi, W. (2015). The Relationship between CRM Strategies Stage on Competitive Advantage: An Analytical Perspective. International Journal of Business and Management, 10(8), 245-251. http://dx.doi.org/10.5539/ijbm.v10n8p245

Heskett, J. I., Jones, T. O., Loveman, G. W., Sasser, W. E., \& Schlesinger, L. A. (1994). Putting the Service Profit Chain to Work. Best of Harvard Business Review (HBR), July-Aug, 164-170. https://hbr.org/2008/07/putting-the-service-profit-chain-to-work

Homburg, C., Wieseke, J., \& Hoyer, W. D. (2009). Social Identity and Service Profit Chain. Journal of Marketing, 73(2), 38-54. http://dx.doi.org/10.1509/jmkg.73.2.38

Johnston, R. (1999). Service Operations management: return to roots. International Journal of Operation \& Production Management, 19(2), 104-124. http://dx.doi.org/10.1108/0144357051063366

Kodama, M. (2006). Knowledge-based view of corporate strategy. Technovation, 26(12), 1390-1406. 
http://dx.doi.org/10.1016/j.technovation.2005.08.006

Lazovic, S. (2012). The Role and Importance of Emotional Intelligence in Knowledge Management. Retrieved from https://ideas.repec.org/h/isv/mklp12/797-805.html

Nadeem, M. (2015). Employee's (Happy) Branding Corporate's 'Social' Reputation Can You Put a Price on That? International Journal of Marketing Studies, 7(6), 116-129. http://dx.doi.org/10.5539/ijms.v7n6p116

Rowley, J. (2005). Four C's of customer loyalty. Marketing Intelligence and Planning, 23(6), 574-581. http://dx.doi.org/10.1108/02634500510624138

Schlesinger, L. A., \& Heskett, J. L. (1991). Breaking the cycle of failure in service. Solan Management Review, $32(3), 17-28$.

Shen, H. (2015). Critical Success Factors for Leading Hotel Brands in Asia: A Case Study of Banyan Tree International Journal of Marketing Studies, 7(3), 19-26. http://dx.doi.org/10.5539/ijms.v7n3p19

Slatten, T., \& Mehmetoglu, M. (2011). Antecedents and effects of engaged frontline employees. Managing Service Quality, 21(1), http://dx.doi.org/10.1108/09604521111100261

Sureshchandar, G. S., Rajendran, C., \& Anantharaman, R. N. (2002). The relationship between service quality and customer satisfaction: a factor specific approach. Journal of Service Marketing, 16(4), 363-379. http://dx.doi.org/10.1108/08876040210433248

Theoharakis, V., Sajtos, L., \& Hooley, G. (2009). The strategic role of relational capabilities in the business-to-business service profit chain. Industrial Marketing Management, 38, 914-924. http://dx.doi.org/10.1016/j.indmarman.2009.04.006

Van, N. T., Tuan, N. M., Hoang, T. P., \& Minh, L. P. (2016). The Relationship between Customer Relationship Management and Using Decision to the Product Service of Customers: A Case Study in Vietnam. International Journal of Marketing Studies, 8(1), 102-116. http://dx.doi.org/10.5539/ijms.v8n1p107

Vo, T. N. T., \& Nguyen, C. T. K. (2015). Factors Influencing Customer Perceived Quality and Purchase Intention toward Private Labels in the Vietnam Market, The Moderating Effects of Store Image. International Journal of Marketing Studies, 7(4), 51-63. http://dx.doi.org/10.5539/ijms.v7n4p51

Wisner, P. S., Stringfellow, A., Youngdahl, W. E., \& Parker, L. (2005). The service volunteer - loyalty chain: an exploratory study of charitable not-for-profit service organization. Journal of Operation Management, 23, 143-161. http://dx.doi.org/10.1016/j.jom.2004.07.003

Yee, R. W. Y., Yeung, A. C. L., \& Cheng, C. E. C. (2011). An empirical Analysis in high contact service industries. International Journal of Production Economics, 130, 236-245. http://dx.doi.org/10.1016/j.ijpe.2011.01.001

\section{Copyrights}

Copyright for this article is retained by the author, with first publication rights granted to the journal.

This is an open-access article distributed under the terms and conditions of the Creative Commons Attribution license (http://creativecommons.org/licenses/by/4.0/). 